\title{
Grafting the Indeterminate Tomato Cultivar Moneymaker onto Multifort Rootstock Improves Cold Tolerance
}

\author{
David H. Suchoff ${ }^{1}$ \\ Department of Horticultural Science, North Carolina State University, \\ Raleigh, NC 27695
}

Penelope Perkins-Veazie

Department of Horticulture Science, North Carolina State University

Research Campus, Kanapolis, NC 28081

Heike W. Sederoff

Department of Plant and Microbial Biology, North Carolina State University, Raleigh, NC 27695

\section{Jonathan R. Schultheis}

Department of Horticultural Science, North Carolina State University, Raleigh, NC 27695

\author{
Matthew D. Kleinhenz \\ Department of Horticulture and Crop Science, The Ohio State University, \\ Wooster, OH 44691
}

\section{Frank J. Louws}

Department of Entomology and Plant Pathology, North Carolina State University, Raleigh, NC 27695; and NSF Center for Integrated Pest Management, North Carolina State University, Raleigh, NC 27695

\section{Christopher C. Gunter}

Department of Horticultural Science, North Carolina State University, Raleigh, NC 27695

Additional index words. Solanum habrochaites, Solanum lycopersicum, herbaceous grafts, root system morphology, suboptimal temperature

Abstract. Tomato (Solanum lycopersicum L.) is a warm-season, cold-sensitive crop that shows slower growth and development at temperatures below $18^{\circ} \mathrm{C}$. Improving suboptimal temperature tolerance would allow earlier planting of field-grown tomato and a reduction in energy inputs for heating greenhouses. Grafting tomato onto high-altitude Solanum habrochaites (S. Knapp and D.M. Spooner) accessions has proven effective at improving scion suboptimal temperature tolerance in limited experiments. This study was conducted to determine whether commercially available tomato rootstocks with differing parental backgrounds and root system morphologies can improve the tolerance of scion plants to suboptimal temperature. Two controlled environment growth chambers were used and maintained at either optimal $\left(25^{\circ} \mathrm{C}\right.$ day $/ 20^{\circ} \mathrm{C}$ night $)$ or suboptimal $\left(15^{\circ} \mathrm{C}\right.$ day $/ 15^{\circ} \mathrm{C}$ night $)$ temperatures. The cold-sensitive tomato cultivar Moneymaker was used as the nongrafted and self-grafted control as well as scion grafted on 'Multifort' $(S$. lycopersicum $\times S$. habrochaites), 'Shield' (S. lycopersicum), and S. habrochaites LA1777 rootstocks. Plants were grown for 10 days in $3.8 \mathrm{~L}$ plastic containers filled with a mixture of calcined clay and sand. 'Multifort' rootstock significantly reduced the amount of cold-induced stress as observed by larger leaf area and higher levels of $\mathrm{CO}_{2}$ assimilation and photosystem II quantum efficiency. 'Multifort' had significantly longer roots, having $42 \%$ to $56 \%$ more fine root (diameter less than $0.5 \mathrm{~mm}$ ) length compared with the other nongrafted and grafted treatments. Leaf starch concentration was significantly lower in 'Multifort'-grafted plants at suboptimal temperatures compared with the self-grafted and nongrafted controls and the 'Shield'-grafted plants at the same temperature. The ability for 'Multifort' to maintain root growth at suboptimal temperatures may improve root system sink strength, thereby promoting movement of photosynthate from leaf to root even under cold conditions. This work demonstrates that a commercially available rootstock can be used to improve suboptimal temperature tolerance in cold-sensitive 'Moneymaker' scions.

Modern commercial tomato (S. lycopersicum) varieties originate from subtropical regions of South America, and temperatures between 18 and $25{ }^{\circ} \mathrm{C}$ are required for optimal growth and fruit production (Criddle et al., 1997; Ntatsi et al., 2017; Van Der
Ploeg and Heuvelink, 2005). When exposed to nonfreezing, suboptimal temperatures, tomato shows a marked decline in growth and yield (Van Der Ploeg and Heuvelink, 2005). This reduction in growth at suboptimal temperatures is due to numerous cellular, biochemical, and physiological changes (Allen and Ort, 2001).

Photosynthesis in tomato and other warmseason crops is affected directly and indirectly by suboptimal temperatures (Allen and Ort, 2001). Nearly all major components of photosynthesis, including photosystems I and II, the electron transport chain, and RuBisCO (ribulose-1, 5-bisphosphate carboxylase/oxygenase) show a decline in efficiency with cold stress (Allen and Ort, 2001; Kingston-Smith et al., 1997; Lynch, 1990). This is further exacerbated by a reduction in the amount of assimilable $\mathrm{CO}_{2}$ caused by cold-induced stomatal closure (Allen and Ort, 2001). In response to cold soils, root system growth and carbon sink strength are reduced, resulting in a slowing of photosynthate export from the leaves and concurrent increase in leaf soluble sugar and starch concentrations (Ainsworth and Bush, 2011; Ntatsi et al., 2014; Rosa et al., 2009). Although accumulated soluble sugars can have a protective effect in cold-stressed plant tissue (Gupta and Knaur, 2005), increased leaf-sucrose and starch concentrations lead to a downregulation of photosynthetic activity (Chiou and Bush, 1998; Goldschmidt and Huber, 1992; Paul and Foyer, 2001).

To limit growth retardation and yield loss induced by cold stress, tomato produced in temperate regions is grown during summer months or in heated greenhouses. Improved tolerance to suboptimal temperatures in tomato would lead to a reduction in $\mathrm{CO}_{2}$ emissions generated from the burning of fossil fuels used to heat greenhouses. Furthermore, cold-tolerant tomato varieties could improve early season growth and production, allowing growers to meet more lucrative early season markets. For example, in 2018, growers could receive as much as $\$ 0.16$ more per pound of field-grown tomatoes in March than in June (USDA ERS, 2018).

High-altitude wild tomato relatives exist that are more tolerant to suboptimal temperatures than cultivated $S$. lycopersicum (Venema et al., 1999). Unfortunately, breeding interspecific hybrids that maintain elite fruit qualities and are tolerant to suboptimal temperatures have not proven effective (Schwarz et al., 2010; Venema et al., 2005).

One way to bypass breeding difficulties is through grafting cold-sensitive elite tomato lines onto cold-tolerant rootstocks. The highaltitude wild tomato relative $S$. habrochaites is known to be more tolerant of suboptimal temperatures (Venema et al., 1999, 2005) and has been the subject of numerous grafting studies. Venema et al. (2008) found that grafting the cold-sensitive $S$. lycopersicum cultivar Moneymaker onto $S$. habrochaites line accession LA1777 improved shoot growth rate and total leaf area compared with selfgrafted 'Moneymaker' when grown at $15{ }^{\circ} \mathrm{C}$ 
root zone temperature. The authors attributed this improved cold tolerance to the ability of LA1777 to maintain strong root growth as seen in an increased root:shoot dry weight ratio, which they hypothesized allowed for improved water and nutrient absorption even at low temperatures. A reduction in root hydraulic conductance is a common stress response to suboptimal temperatures (Equiza et al., 2001; Fennell and Markhart, 1997). Roots of S. lycopersicum and $S$. habrochaites showed this decrease in hydraulic conductance at lower temperatures, but these values did not differ between species (Bloom et al., 2004).

Root system morphology plays a critical role in hydraulic conductance. Plants with thin average root diameter show marked increase in root hydraulic conductivity (Ho et al., 2005; Huang and Eissenstat, 2000; Rieger and Litvin, 1999). Little is known about the root system morphology of $S$. habrochaites. Furthermore, numerous commercially available interspecific tomato rootstocks $(S$. lycopersicum $\times S$. habrochaites $)$ exist but have not been investigated for cold tolerance. To address these research gaps, the following study was conducted to 1) compare shoot growth, photosynthetic activity, and leaf photosynthate concentrations of a coldsensitive tomato cultivar when grafted onto an intraspecific tomato hybrid ( $S$. lycopersicum) rootstock, an interspecific tomato hybrid (S. lycopersicum $\times S$. habrochaites), and a wild accession ( $S$. habrochaites) at optimal and suboptimal temperatures and 2) determine if differences exist among the rootstock root system morphologies at different temperatures.

\section{Materials and Methods}

Controlled environment. This study was conducted in two growth chambers $(2.4 \mathrm{~m}$ wide $\times 3.7 \mathrm{~m}$ depth $\times 2.1 \mathrm{~m}$ height) in the North Carolina State University Phytotron (Raleigh, NC). Chambers were lit daily for $14 \mathrm{~h}$ with $\mathrm{T}-5$ fluorescent and incandescent bulbs so that plants received photosynthetic photon flux density (PPFD) of $500 \mu \mathrm{mol} \cdot \mathrm{m}^{-2} \cdot \mathrm{s}^{-1}$. Chamber temperatures were designated as optimal $\left(25^{\circ} \mathrm{C}\right.$ day/ $20{ }^{\circ} \mathrm{C}$ night $)$ and suboptimal $\left(15{ }^{\circ} \mathrm{C}\right.$ day $/$ $15{ }^{\circ} \mathrm{C}$ night). This suboptimal temperature treatment was chosen as it caused severe cold-stress-induced reduction in leaf area and fresh weight in self-grafted 'Moneymaker' (Venema et al., 2008). Chambers were maintained at $70 \%$ relative humidity and 400 parts per million (ppm) ambient $\mathrm{CO}_{2}$.

Received for publication 19 June 2018. Accepted for publication 4 Sept. 2018.

This material is based on work that is supported by the National Institute of Food and Agriculture, U.S. Department of Agriculture, under award number 2016-51181-25404.

${ }^{1}$ Corresponding author. E-mail: dhsuchof@ncsu. edu.
Plant material. The indeterminate tomato cultivar Moneymaker (West Coast Seeds, Delta, BC, Canada) was used because of its published sensitivity to cold (Ntatsi et al., 2014, 2017). Two commercially available rootstocks ['Multifort' (De Ruiter, St. Louis, MO) and 'Shield' (Rijk Zwaan, Salinas, CA)] were used as they are known to have significantly different root system morphologies (Suchoff et al., 2017). Although both rootstocks are hybrids, 'Multifort' is interspecific $(S$. lycopersicum $\times S$. habrochaites) whereas 'Shield' is intraspecific (S. lycopersicum). The wild tomato species S. habrochaites line accession LA1777 (LA1777; C.M. Rick Tomato Genetics Resource Center, UC Davis, CA) was used because of its documented cold tolerance (Ntatsi et al., 2014, 2017; Venema et al., 2008). In total, there were five graft treatments: 'Moneymaker' nongrafted (M-NG), 'Moneymaker' self-grafted (M/Money), 'Moneymaker' on 'Multifort' (M/Multifort), 'Moneymaker' on 'Shield' (M/Shield), and 'Moneymaker' on S. habrochaites (M/LA1777).

All seedlings were started in the optimal growth chamber. Seeds were sown in 72-cell plug trays (T.O. Plastics, Clearwater, MN) filled with a $2: 1 \mathrm{v} / \mathrm{v}$ mixture of calcined clay (Turface MVP; Profile Products LLC, Buffalo Grove, IL) and sand (\#20 Pool Filter Sand; Aquabrite ${ }^{\circledR}$, Pleasanton, CA). This mixture maintains similar physical properties as field soil and allows thorough and clean extraction of roots (Manavalan et al., 2010; Suchoff et al., 2017). Following the recommendations of Venema et al. (2008) for successful grafting of LA1777, seeds of the wild accession were sown $10 \mathrm{~d}$ before all other seeds because of its slow germination and initial growth. The M-NG control was sown $5 \mathrm{~d}$ after all rootstocks and self-grafted control to account for the 5-d healing process so that all plants were at a similar physiological stage. Grafting using the Japanese tubegraft method (Rivard and Louws, 2006) occurred when rootstock and scion hypocotyls were $\approx 2 \mathrm{~mm}$ in diameter and had two to three true leaves. Both scion and rootstock were cut at a $45^{\circ}$ angle below the cotyledons and the resultant graft union held together using a 2.0-mm diameter graft clip. Grafts were healed in transparent plastic storage bins $(67.3 \mathrm{~cm}$ length $\times 40.6 \mathrm{~cm}$ height $\times 31.8 \mathrm{~cm}$ width; Sterilite ${ }^{\circledR}$, Townsend, MA) placed under a bench within the chamber. Storage bins were covered with the supplied transparent lid, which maintained the internal relative humidity at $98 \%$ and allowed light penetration of $\approx 100 \mu \mathrm{mol} \cdot \mathrm{m}^{-2} \cdot \mathrm{s}^{-1}$ $P P F D$ for $14 \mathrm{~h}$ each day. During the 5-d healing process, the plants were slowly acclimated to reduced relative humidity by gradually opening the top of the storage bin until it was completely off on day 5. All plants were transplanted $2 \mathrm{~d}$ after removal from the healing bins into 3.8 -L plastic pots, with dimensions of $20.3 \mathrm{~cm}$ (top diameter) $\times$ $20.3 \mathrm{~cm}$ (height) $\times 17.8 \mathrm{~cm}$ (bottom diameter, 8 Standard Growing Container; Belden Plastics, St. Paul, MN) lined with woven $20 \times 20$ mesh of $0.02 \mathrm{~cm}$ diameter thread $(\approx 0.016$ $\mathrm{cm}^{2}$ opening size, Clear Advantage Charcoal Fiber Glass Insect Screen; New York Wire, Hanover, PA) and filled with the calcined clay and sand media. The woven mesh was used to keep the media from falling through pot drainage holes and aid in root ball extraction.

Experimental setup. All plants were acclimated to the optimal chamber for $5 \mathrm{~d}$ after transplanting, after which four plants of each graft treatment (four replications per subplot treatment) were moved into the suboptimal and optimal chambers $(n=20$ pots per chamber). Pots were arranged in a completely randomized design within the chambers and moved daily to account for any potential light or air movement gradients. Plants were grown for $10 \mathrm{~d}$ in each chamber; allowing plants to grow beyond this period would result in the plants becoming pot-bound, confounding root system morphology measurements. During the 10 -d period, all plants were watered and fertilized (200 ppm of 20N-4.4P-16.6K, Peters Professional; JR Peters, Inc., Allentown, PA) on days 1 and 5 and watered as needed. Water and fertilizer temperatures were tempered to match that of the chamber in which they were used.

Data collection. Temperature sensors (MPS-6; METER Group, Pullman, WA) were placed in the center of two representative selected pots per chamber and soil temperature was collected using a data logger (EM50; METER Group). One day before termination of each experimental trial, leaf gas exchange and fluorescence measurements were collected. Measurements were taken on the terminal leaflet of the most recent fully expanded leaf using an open gas exchange system coupled with a leaf chamber fluorometer (LI-6800; LI-COR, Inc., Lincoln, NE). Net $\mathrm{CO}_{2}$ assimilation $\left(A, \mu \mathrm{mol} \cdot \mathrm{m}^{-2} \cdot \mathrm{s}^{-1}\right)$, stomatal conductance $\left(g_{\mathrm{S}}\right.$, $\left.\mathrm{mmol} \cdot \mathrm{m}^{-2} \cdot \mathrm{s}^{-1}\right)$, effective quantum yield of photosystem II $\left(\varphi_{\text {PSII }}\right)$, and photochemical quenching $(q P)$ were measured between 11:00 AM and 1:00 PM on light-acclimated leaves. $P P F$ density within the leaf chamber was set to $500 \mu \mathrm{mol} \cdot \mathrm{m}^{-2} \cdot \mathrm{s}^{-1}$, with temperature and relative humidity maintained at levels matching those inside each growth chamber. The sensor head was left on each leaflet for 2-3 min until values of $A$ and $g_{\mathrm{S}}$ stabilized. Minimal $\left(F_{\mathrm{o}}\right)$ and maximal $\left(F_{\mathrm{m}}\right)$ fluorescence values were obtained from darkadapted leaves $3 \mathrm{~h}$ after lights were turned off within the growth chambers. These values were used to calculate maximum quantum yield of photosystem II $\left(F_{\mathrm{v}} / F_{\mathrm{m}}\right.$, where $F_{\mathrm{v}}=$ $F_{\mathrm{m}}-F_{\mathrm{o}}$ ). On termination of the study, the same leaf from which gas exchange and fluorescence data were collected was separated, it's fresh weight and leaf area measured (LI-3100C area meter; LI-COR, Inc.), and then the leaf was immediately frozen in liquid nitrogen. These samples were stored at $-80{ }^{\circ} \mathrm{C}$ until analysis of sugar and starch concentrations. The remaining leaves from each plant were separated from the stem, weighed, and leaf area was measured. 
Starch and sugar quantification. Soluble sugars and starch content from freeze-dried leaf tissue were determined using highperformance liquid chromatography (HPLC) based on established protocols (Chow and Landhäusser, 2004; Smith and Zeeman, 2006; Warren et al., 2015). A 0.01-g sample of the ground tissue was mixed with $0.3 \mathrm{~mL}$ of $80 \%$ ethanol in a $2.0-\mathrm{mL}$ centrifuge tube and incubated for $3 \mathrm{~min}$ in a boiling water bath to stop enzymatic action. Following boiling, samples were allowed to cool to room temperature for $\approx 5 \mathrm{~min}$. Once cool, $0.7 \mathrm{~mL}$ of $80 \%$ ethanol was added to the sample and vortexed for $1 \mathrm{~min}$, and then centrifuged at $14,000 \mathrm{rpm}$ at $4{ }^{\circ} \mathrm{C}$ for $20 \mathrm{~min}$ (5417R Refrigerated Centrifuge; Eppendorf, Hauppauge, NY). The resultant supernatant was collected. An additional $0.6 \mathrm{~mL}$ of $80 \%$ ethanol was added to the pellet, which was vortexed for $1 \mathrm{~min}$ and centrifuged at 14,000 $\mathrm{rpm}$ at $4{ }^{\circ} \mathrm{C}$ for $20 \mathrm{~min}$. The supernatant was collected and combined with the prior collected supernatant. Both the pellet and supernatant were dried completely for $80 \mathrm{~min}$ in a vacuum concentrator (Savant DNA120 SpeedVac concentrator; Thermo Fisher Scientific, Waltham, MA).

The dried supernatant was vortexed for $1 \mathrm{~min}$ with $1 \mathrm{~mL}$ of distilled deionized water and filtered into HPLC vials with $0.2 \mu \mathrm{m}$ filters (Target2 nylon Syringe filters; Thermo Fisher Scientific). A $5-\mu \mathrm{L}$ aliquot was injected onto a Rezex RCM-Monosaccharide $\mathrm{Ca}+2(8 \%), 00 \mathrm{H}-0130-\mathrm{KO}(300 \times 7.8 \mathrm{~mm})$ column equipped with a Carbo-CA guard cartridge (Phenomenex, Torrance, CA) attached to a L 2130 pump (Hitachi High Technologies, San Jose, CA). The column was eluted with water at a flow rate of $0.6 \mathrm{~mL} \cdot \mathrm{min}^{-1}$ and kept at a temperature of $55{ }^{\circ} \mathrm{C}$. The soluble sugars glucose, fructose, and sucrose were detected using an IR detector (L-2490; Hitachi) at $45^{\circ} \mathrm{C}$ and quantified using standard curves from sucrose, glucose, and fructose (Sigma Aldrich Co., St. Louis, MO). Chromatographic data were stored and processed (LaChrom Elite equipped with D-2000 software; Hitachi High Technologies).

Starch content was determined using the dried pellet. The material was resuspended in $0.5 \mathrm{~mL} \mathrm{H}_{2} \mathrm{O}$ and sonicated for 10 min (Bransonic 3510 Ultrasonic Cleaner; Branson, Danbury, CT). Starch within the sample was gelatinized by heating to $100{ }^{\circ} \mathrm{C}$ for $10 \mathrm{~min}$. Samples were cooled for $5 \mathrm{~min}$ and $0.5 \mathrm{~mL}$ of $200 \mathrm{~mm}$ sodium acetate $(\mathrm{pH}$ 5.5) added, followed by $200 \mu \mathrm{L}\left(2 \mathrm{mg} \cdot \mathrm{mL}^{-1}\right)$ of amyloglucosidase (Aspergillus nigerderived; Sigma Aldrich Co.) and $10 \mu \mathrm{L}$ of $\alpha$-amylase (100U porcine pancreas-derived; Millipore Sigma, St. Louis, MO). Tomato starch control tubes were prepared the same way as the samples, except that controls contained solely $210 \mu \mathrm{L}$ of $200 \mathrm{~mm}$ sodium acetate ( $\mathrm{pH}$ 5.5). All tubes were incubated at $37^{\circ} \mathrm{C}$ for $4 \mathrm{~h}$, followed by centrifugation at $14,000 \mathrm{rpm}$ for $20 \mathrm{~min}$ at $4{ }^{\circ} \mathrm{C}$. Supernatants were filtered and run in the HPLC using the above method for soluble sugars, and starch content was determined based on the glucose equivalents.

Root system analysis. Root balls were excavated from the pot, rinsed free of media, and then placed in $0.5 \mathrm{~g} \cdot \mathrm{L}^{-1}$ neutral red dye solution (Sigma Aldrich Co.) for $24 \mathrm{~h}$ at $6.7{ }^{\circ} \mathrm{C}$. Following the dying process, roots were rinsed and placed in a $30 \times 42-\mathrm{cm}$ acrylic tray filled with $3 \mathrm{~cm}$ of water and scanned at 800 dots per inch using a flatbed scanner (Epson Expression $^{\circledR}$ 10000XL; Epson America, Long Beach, CA). A root system image analysis software (WinRHIZO v. 2012b; Regent Instruments, Inc., Quebec, Canada) was used to analyze the scanned images to obtain root morphological data including average root diameter, total root length (TRL), and length per diameter class (diameter classes were in increments of $0.5 \mathrm{~mm}$ ). Relative diameter class length (RDCL) was calculated by dividing each diameter class length (DCL) by the TRL, giving the proportion of root length composed of each diameter class. Roots were dried at $70{ }^{\circ} \mathrm{C}$ for $24 \mathrm{~h}$ and total root system dry weight used to calculate specific root length (SRL) (TRL/root dry weight).

The study was repeated, but temperatures were switched between chambers so that temperature was not nested within chamber, giving two experimental trials.

Data analysis. Data were analyzed using the GLIMMIX procedure in SAS v 9.4 (SAS Institute, Inc., Cary, NC). To avoid issues of pseudoreplication in the analysis, data from both experimental trials were combined and the results were analyzed as a split-plot design, where temperature represented the whole plot treatment and graft the split-plot treatment. The whole-plot error term was the experimental trial and the split-plot error term was the chamber $\times$ experimental trial. Proportion data $\left(\varphi_{\mathrm{PSII}}, q P, F_{\mathrm{v}} / F_{\mathrm{m}}, \mathrm{RDCL}\right)$ were analyzed using a beta distribution and the Pearson chi-squared statistics divided by the $\mathrm{df}(\varphi)$ were checked for overdispersion and distribution goodness-of-fit. Leaf area, TRL, and SRL data showed strong heteroscedasticity, which was ameliorated through square root transformations. All transformed data were back-transformed for presentation. Any effect found to be significant $(P<0.05)$ was further analyzed with Tukey's honest significant difference post hoc mean separation test.

\section{Results}

Temperatures were similar between experimental trials (Fig. 1A-D). Soils showed diurnal temperature variation for both experimental trials (Fig. 1C and D). Ambient temperatures in the suboptimal temperature chamber were maintained at $15{ }^{\circ} \mathrm{C}$ (Fig. 1A and B). Suboptimal soils showed warming most likely because of absorption of light energy; however, the range (15 to $18{ }^{\circ} \mathrm{C}$; Fig. $1 \mathrm{C}$ and $\mathrm{D})$ and magnitude $\left( \pm 3^{\circ} \mathrm{C}\right)$ of this warming were lower than that of optimal temperature soils, which ranged from 20 to $26^{\circ} \mathrm{C}$, with a magnitude of $\pm 6{ }^{\circ} \mathrm{C}$.
Shoot morphology and physiology. The interaction of graft and temperature was significant for total leaf area (Table 1). At optimal temperature, there were no differences among M-NG, M/Money, M/Shield, or M/Multifort (Fig. 2A). M/LA1777 had significantly lower leaf area than M/Multifort and $\mathrm{M}-\mathrm{NG}$, but was not different from $\mathrm{M} /$ Money or M/Shield. At suboptimal temperature, there was a decline in total leaf area in $\mathrm{M} / \mathrm{NG}, \mathrm{M} / \mathrm{Money}$, and M/Shield, compared with the same treatments at optimal temperature except for M/Multifort, which maintained total leaf area similar to all graft treatments at optimal temperature. Furthermore, leaf area of M/Multifort at suboptimal temperature was not significantly different from the same graft treatment at optimal temperature. Only the main effect of temperature affected $g_{\mathrm{S}}$ (Table 1); values at optimal temperature were higher than suboptimal (Table 2). Similarly, $q P, F_{\mathrm{v}} / F_{\mathrm{m}}$, and $\varphi_{\text {PSII }}$ showed a significant depression at suboptimal temperature (Table 2). These photosynthetic responses were affected by graft treatments; values for all three were highest in $\mathrm{M} /$ Multifort. Values of $\varphi_{\mathrm{PSII}}$ and $q P$ for $\mathrm{M} /$ Multifort were significantly higher than those for M-NG and M/Money (Table 3). Fewer differences were observed in $F_{\mathrm{v}} / F_{\mathrm{m}}$; M-NG had a lower $F_{\mathrm{v}} / F_{\mathrm{m}}$ than M/Multifort (Table 2).

The interaction of graft and temperature was significant for foliar starch concentration (Table 1). At optimal temperature, there were no differences observed among the graft treatments; however, at suboptimal temperature, M/LA1777 and M/Multifort had significantly lower starch concentrations than the remaining three graft treatments (Fig. 2B). There was no significant main effect or interaction for the individual or combined leaf-soluble sugar concentrations (Table 1).

Net $\mathrm{CO}_{2}$ assimilation rate $(A)$ was the only photosynthetic response affected by the interaction of graft and temperature (Table 1). Values of $A$ were highest in M/Multifort at optimal temperatures compared with M-NG, M/Money, and M/LA1777, but was similar to $\mathrm{M} /$ Shield (Fig. 2C). At suboptimal temperature, these values dropped in all graft treatments compared with the same graft treatments at optimal temperature. M/Multifort maintained the highest values of $A$ at suboptimal temperature compared with M-NG, $\mathrm{M} /$ Money, and M/Shield, although it was not different from M/LA1777.

Root morphology. Average root diameter, TRL, and SRL were affected by the interaction of graft and temperature (Table 3). At optimal temperature, TRL was similar for all graft treatments, except for M/LA1777, which had a TRL significantly shorter than M-NG, M/Money, and M/Multifort (Fig. 3A). All graft treatments showed a significant drop in TRL at suboptimal temperature; however, M/Multifort maintained longer TRL than all other graft treatments. Furthermore, TRL values for M/Multifort at suboptimal temperature were no different from TRL for M/Shield and M/LA1777 at optimal 


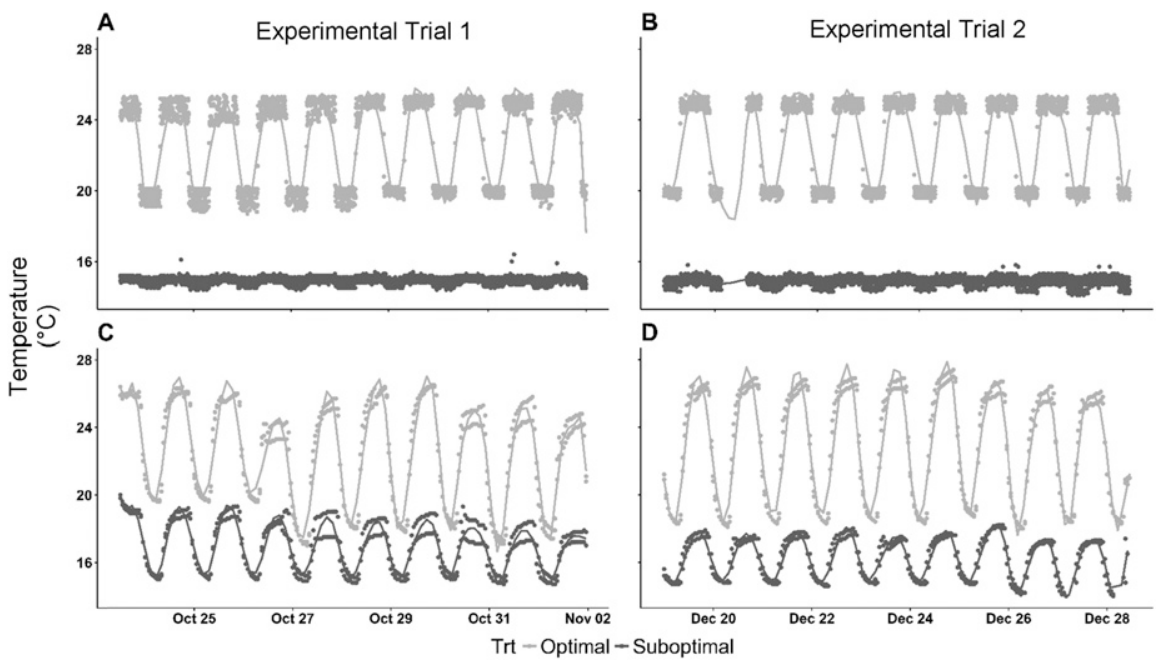

Fig. 1. Experimental trial 1 ambient $(\mathbf{A})$ and soil $(\mathbf{C})$ temperatures and experimental trial two ambient (B) and soil (D) temperatures. Target ambient temperatures for optimal and suboptimal chambers are $25{ }^{\circ} \mathrm{C}$ day $/ 20{ }^{\circ} \mathrm{C}$ night and $15{ }^{\circ} \mathrm{C}$ day $/ 15{ }^{\circ} \mathrm{C}$ night, respectively. Soil temperatures were measured with matric water potential and temperature sensors (MPS-6; METER Group, Pullman, WA) placed in the center of two pots per chamber per experimental trial and stored in a data logger (EM50; METER Group)

Table 1. Results of analysis of variance for the impact of grafting and temperature on the indeterminate tomato cultivar Moneymaker shoot morphology and physiology when grown in growth chambers maintained at either $25^{\circ} \mathrm{C}$ day $/ 20^{\circ} \mathrm{C}$ or $15^{\circ} \mathrm{C}$ day $/ 15^{\circ} \mathrm{C}$ night.

\begin{tabular}{|c|c|c|c|c|c|c|c|c|c|c|c|c|}
\hline Effect & $\mathrm{df}$ & $\begin{array}{l}\text { Leaf } \\
\text { area }\end{array}$ & $g_{\mathrm{S}}^{\mathrm{z}}$ & $A^{\mathrm{y}}$ & $\Phi_{\text {PSII }}{ }^{\mathrm{x}}$ & $F_{\mathrm{v}} / F_{m}{ }^{\mathrm{w}}$ & $q P^{\mathrm{v}}$ & Sucrose $^{u}$ & Glucose & Fructose & $\begin{array}{c}\text { Total } \\
\text { soluble } \\
\text { sugars }\end{array}$ & Starch \\
\hline$\overline{\text { Graft }}$ & 4 & $* * *$ & NS & $* * *$ & $* *$ & $* *$ & $* *$ & NS & NS & NS & NS & $* * *$ \\
\hline Tempera & 1 & $* * *$ & $* * *$ & $* * *$ & $* * *$ & $* * *$ & $* * *$ & NS & NS & NS & NS & * \\
\hline Graft $\times$ Temperature & 4 & $*$ & NS & * & NS & NS & NS & NS & NS & NS & NS & $* * *$ \\
\hline
\end{tabular}

${ }^{\mathrm{z}}$ Stomatal conductance.

${ }^{\mathrm{y}} \mathrm{Net} \mathrm{CO}_{2}$ assimilation rate.

${ }^{\mathrm{x}}$ Effective quantum yield of photosystem II.

${ }^{\mathrm{w}}$ Maximum quantum yield of photosystem II.

${ }^{\mathrm{v}}$ Photochemical quenching.

"Soluble sugars (sucrose, glucose, and fructose) and starch concentrations measured from a single leaf via high-performance liquid chromatography.

Ns, ${ }^{*}, * * * * * *$ Nonsignificant at $P \leq 0.05$ or significant at $P \leq 0.05,0.01$, or 0.001 , respectively.

temperature. Average root diameter was similar among $\mathrm{M}-\mathrm{NG}, \mathrm{M} /$ Money, and M/Shield at optimal temperature (Fig. 3B). At this temperature, M/LA1777 and M/Multifort average root diameter values were similar and significantly thinner than the aforementioned three graft treatments. At suboptimal temperature, all graft treatments showed a reduction in average root diameter with no differences observed among them. In addition, the average root diameter of M/LA1777 and $\mathrm{M} /$ Multifort at optimal temperature was no different from the values of M-NG, $\mathrm{M} /$ Money, and M/Shield at suboptimal temperature. Values of SRL at optimal temperature were similar among all graft treatments (Fig. 3C). At suboptimal temperature, SRL dropped significantly in M-NG and M/Money. $\mathrm{M} /$ Shield showed a similar reduction in SRL with suboptimal temperature; however, this drop was not statistically significant. Both M/ LA1777 and M/Multifort showed no reduction in SRL with suboptimal temperature and maintained SRL similar to all graft treatments at optimal temperature.
Diameter class length 1 was affected by the graft $\times$ temperature interaction (Table 3 ). At optimal temperature, all graft treatments had similar DCL1 values, except for M/LA1777 (5082.75 cm; Table 4), which was significantly less than M-NG, M/Money, and M/ Multifort. These values dropped with suboptimal temperature, and at this temperature treatment, M/Multifort maintained DCL1 values $(5166.28 \mathrm{~cm})$ significantly longer than all other graft treatments. This difference amounts to $42 \%$ to $56 \%$ more fine root length in $\mathrm{M} /$ Multifort compared with all other graft treatments at suboptimal temperatures. Relative DCL 1 was similar among the graft treatments at optimal temperature $(\approx 0.80)$, and all but M/Multifort showed a significant drop in RDCL1 at suboptimal temperatures. This graft treatment was able to maintain similar RDCL1 values at optimal and suboptimal temperatures $(0.7959$ and 0.7945 , respectively). DCL2 was affected by both the main effects of graft and temperature, but not the interaction (Table 3). DCL2 was highest at optimal temperature $(1378.17 \mathrm{~cm}$;
Table 4). M/Multifort had the largest DCL2 $(1412.13 \mathrm{~cm})$, which was similar to M-NG $(1273.72 \mathrm{~cm})$. The lowest DCL2 value was observed in M/LA1777 (997.86 cm). Unlike DCL2, RDCL2 was significantly affected by the graft $\times$ temperature interaction (Table 2). At optimal temperature, M/LA1777 RDCL2 (0.1659; Table 4) was significantly higher than M/Money (0.1385). All graft treatments showed a significant increase in RDCL2 at suboptimal temperature and these values were similar among the graft treatments. However, RDCL2 for M/Multifort at suboptimal temperature $(0.1816)$ was no different from all graft treatments at optimal temperature, except for M/Money. DCL3 was affected by the main effects of graft and temperature and RDCL3 was only affected by temperature main effect (Table 3). DCL3 was highest at optimal temperature compared with suboptimal temperature (314.94 and $263.56 \mathrm{~cm}$, respectively; Table 4). Values of RDCL3 showed an opposite response, with suboptimal $(0.0511)$ being higher than optimal (0.0350). Finally, M/Multifort and M-NG had the highest DCL3 values (356.66 and $318.81 \mathrm{~cm}$, respectively). The lowest DCL3 was observed in M/LA1777 (221.53 cm).

\section{Discussion}

Results from this study indicate that the commercially available tomato rootstock 'Multifort' can reduce the amount of suboptimal temperature-induced shoot stress. In contrast with prior work (Ntatsi et al., 2014, 2017; Venema et al., 2008), no growth benefit was observed when using LA1777 as a rootstock in suboptimal temperatures. A general reduction in leaf area with M/LA1777 compared with the other graft treatments occurred. We attribute this general poor growth to graft incompatibility. That is, graft survival rate in M/LA1777 was low $(20 \%$ to $30 \%$; data not shown) compared with the other graft treatments $(>90 \%)$. Bloom et al. (2004) had equal difficulty in successfully grafting onto LA1777 and were unable to generate plants with this rootstock. In our study, those plants that did survive showed unequal growth above and below the graft union, which is indicative of graft incompatibility and poor development of vascular connections (Goldschmidt, 2014; Kawaguchi et al., 2008).

Greenhouse production of tomato requires substantial fossil fuel-derived energy inputs. Increasing energy prices coupled with societal concerns regarding $\mathrm{CO}_{2}$ emissions and its role in climate change require an improvement in energy use efficiency (Ntatsi et al., 2014). Heating a polycarbonate greenhouse between the months of October and March required an energy input of between 134 and $209 \mathrm{kWh} \cdot \mathrm{m}^{-2}$ depending on the location (Fabrizio, 2012). The author calculated the cost of heating to range from $\$ 12.13$ to $\$ 18.13 / \mathrm{m}^{2}$ based on an energy cost of $\$ 0.07 / \mathrm{kWh}$. Relatively small drops in greenhouse temperature settings can result in significant energy savings. For example, reducing 
daytime high temperatures by $2{ }^{\circ} \mathrm{C}$ (19 to $17^{\circ} \mathrm{C}$ ) resulted in a hypothetical $16 \%$ savings in energy costs although it did reduce yearly

marketable fruit by $3.3 \%$ in a representative greenhouse in the Netherlands (Elings et al., 2005). Breeding of more productive tomato
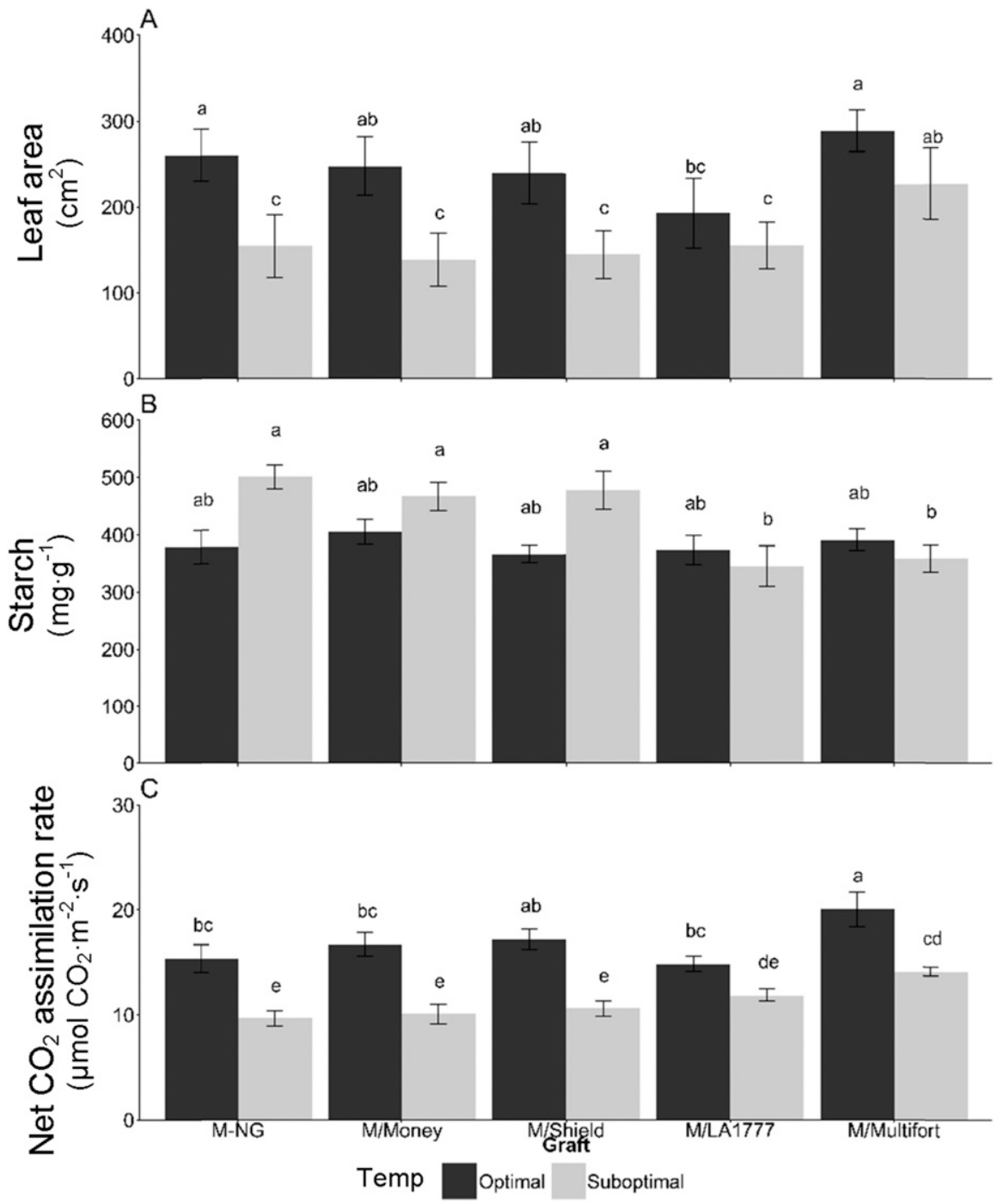

Fig. 2. Effect of grafting and temperature on total leaf area (A), foliar starch concentration $(\mathbf{B})$, and net $\mathrm{CO}_{2}$ assimilation rate $(\mathbf{C}) \pm$ SE. Means with common letters within a response are not different (Tukey's honestly significant difference; $\alpha=0.05$ ) and represent the average of four replications and two experimental trials $(n=8$ data points for each mean). Graft treatments include nongrafted 'Moneymaker' (M-NG), self-grafted 'Moneymaker' (M/Money), 'Moneymaker' grafted onto Solanum habrochaites LA1777 (M/LA1777), 'Moneymaker' grafted onto 'Shield' rootstock (M/Shield), and 'Moneymaker' grafted onto 'Multifort' rootstock (M/Multifort). Temperature regimes were $25^{\circ} \mathrm{C}$ day $/ 20^{\circ} \mathrm{C}$ night (optimal) and $15{ }^{\circ} \mathrm{C}$ day $/ 15{ }^{\circ} \mathrm{C}$ night (suboptimal). varieties has improved energy-use efficiency 2 -fold; however, this improvement is due not to an increase in suboptimal temperature tolerance but an overall increase in yield per unit energy (van der Knijff et al., 2004; Venema et al., 2008).

Breeding efforts directed at improving suboptimal temperature tolerance in $S$. lycopersicum roots and shoots are hindered by lack of genetic variability (Nieuwenhof et al., 1993, 1997, 1999). Wild tomato relatives such as Solanum peruvianum, Solanum chilense, and $S$. habrochaites show a wider range of optimal temperatures for growth and reproduction compared with $S$. lycopersicum (Venema et al., 2005). As discussed prior, when used as a rootstock, LA1777 can improve suboptimal tolerance in susceptible S. lycopersicum scions (Ntatsi et al., 2014, 2017; Venema et al., 2008). Compared with traditional cultivar breeding, grafting compatible scions and rootstocks has the benefit of being customizable; the grower can select the scion variety to meet the market demand while selecting the rootstock to meet the disease pressure and abiotic stress.

LA1777 root systems have been investigated regarding the mechanisms for improved cold tolerance. Venema et al. (2008) observed less suboptimal temperature-induced inhibition of root growth in LA1777 rootstock compared with nongrafted 'Moneymaker'. We observed a similar trend in the 'Multifort' rootstock, which maintained a long, thin diameter root system at suboptimal temperatures. Root systems composed of thin diameter roots maintain higher hydraulic conductivity because of their reduced radial hydraulic resistance and improved absorption (Ho et al., 2005; Huang and Eissenstat, 2000; Rieger and Litvin, 1999). Suboptimal soil temperatures lead to increased viscosity of soil water and consequent reduction in root hydraulic conductance (Equiza et al., 2001). The ability for M/Multifort to produce higher amounts of very thin roots, with improved absorption and hydraulic conductance, may be one of the mechanisms that allows it to tolerate suboptimal temperatures and compensate for increased water viscosity. These results may also explain the improved leaf turgor observed in susceptible tomato lines

Table 2. Main effects of grafting and temperature on photosynthesis and gas exchange on the indeterminate tomato cultivar Moneymaker grown in growth chambers maintained at either $25^{\circ} \mathrm{C}$ day $/ 20^{\circ} \mathrm{C}$ or $15^{\circ} \mathrm{C}$ day $/ 15^{\circ} \mathrm{C}$ night.

\begin{tabular}{|c|c|c|c|c|}
\hline Graft & $g_{\mathrm{s}}^{\mathrm{z}}\left(\mathrm{mol} \cdot \mathrm{m}^{-2} \cdot \mathrm{s}^{-1}\right)$ & $\Phi_{\text {PSII }}{ }^{y}$ & $F_{\mathrm{v}} / F_{m}{ }^{\mathrm{x}}$ & $q P^{\mathrm{w}}$ \\
\hline M/Shield & & $0.4182 \mathrm{ab}$ & $0.8530 \mathrm{ab}$ & $0.6997 \mathrm{ab}$ \\
\hline M/LA1777 & & $0.4087 \mathrm{ab}$ & $0.8488 \mathrm{ab}$ & $0.6933 \mathrm{ab}$ \\
\hline \multicolumn{5}{|l|}{ Temperature } \\
\hline $25^{\circ} \mathrm{C}$ day $/ 20{ }^{\circ} \mathrm{C}$ night & $0.5604 \mathrm{a}$ & $0.5348 \mathrm{a}$ & $0.8775 \mathrm{a}$ & $0.7839 \mathrm{a}$ \\
\hline $15^{\circ} \mathrm{C}$ day $/ 15^{\circ} \mathrm{C}$ night & $0.3682 \mathrm{~b}$ & $0.3043 \mathrm{~b}$ & $0.8272 \mathrm{~b}$ & $0.5764 \mathrm{~b}$ \\
\hline
\end{tabular}

${ }^{\mathrm{z}}$ Stomatal conductance.

${ }^{\mathrm{y}}$ Effective quantum yield of photosystem II.

${ }^{\mathrm{x}}$ Maximum quantum yield of photosystem II.

${ }^{\text {w }}$ Photochemical quenching.

'Means followed by the same letter within response and main effect are not different (Tukey's honestly significant difference; $\alpha=0.05$ ) and represent the average of two experimental trials, four replications, and two temperature treatments for the graft main effect ( $n=16$ data points for each mean) and two experimental trials, four replications, and five graft treatments for the temperature main effect ( $n=40$ data points for each mean).

"'Moneymaker'. 
Table 3. Results of analysis of variance for the impact of graft and temperature on the indeterminate tomato cultivar Moneymaker grown in growth chambers maintained at either $25^{\circ} \mathrm{C}$ day $/ 20^{\circ} \mathrm{C}$ or $15{ }^{\circ} \mathrm{C}$ day/ $15{ }^{\circ} \mathrm{C}$ night.

\begin{tabular}{lcccccccccc}
\hline & & $\begin{array}{c}\text { Avg. } \\
\text { root }\end{array}$ & $\begin{array}{c}\text { Total } \\
\text { root }\end{array}$ & $\begin{array}{c}\text { Specific } \\
\text { root }\end{array}$ & & & & & & \\
Effect & df & diam & length & length & DCL1 & DCL2 & DCL3 & RDCL1 & RDCL2 & RDCL3 \\
\hline Graft & 4 & $* * *$ & $* * *$ & $* *$ & $* * *$ & $* * *$ & $* * *$ & NS & $*$ & NS \\
Temperature & 1 & $* * *$ & $* * *$ & $* * *$ & $*$ & $* * *$ & $* * *$ & $* * *$ & $* * *$ & $* * *$ \\
Graft $\times$ temperature & 4 & $* *$ & $* * *$ & $* * *$ & $* *$ & NS & NS & $* *$ & $*$ & NS \\
\hline
\end{tabular}

${ }^{\mathrm{z}}$ Calculated as total root length divided by root dry weight.

${ }^{\mathrm{y}}$ Diameter class length. DCL1 is the length of roots with diameter less than $0.5 \mathrm{~mm}$, DCL2 is the length of roots with diameters between 0.5 and $1.0 \mathrm{~mm}$, and DCL3 is the length of roots with diameters greater than $1.0 \mathrm{~mm}$.

${ }^{\mathrm{x}}$ Relative diameter class length. RDCL1 is the proportion of total root length composed of roots with diameters less than $0.5 \mathrm{~mm}$, RDCL2 comprises roots with diameters between 0.5 and $1.0 \mathrm{~mm}$, and RDCL3 comprises roots with diameters greater than $1.0 \mathrm{~mm}$.

Ns, ${ }^{*}, * *,{ }^{* * *}$ Nonsignificant at $P \leq 0.05$ or significant at $P \leq 0.05,0.01$, or 0.001 , respectively.
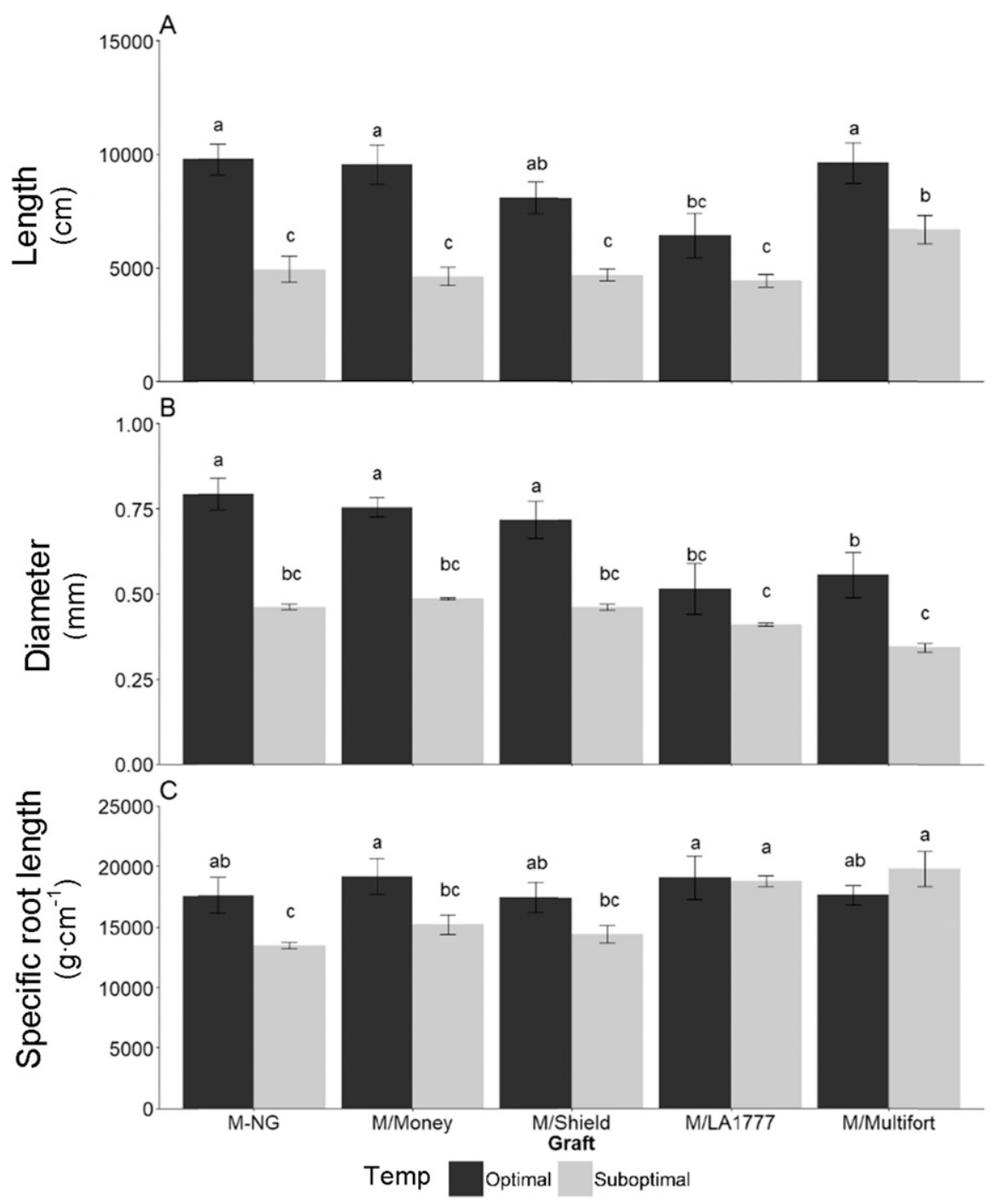

Fig. 3. Effect of grafting and temperature on total root length (A), average root diameter (B), and specific root length $(\mathbf{C}) \pm$ SE. Means with common letters within a response are not different (Tukey's honestly significant difference; $\alpha=0.05)$ and represent the average of four replications and two experimental trials $(n=8$ data points for each mean). Graft treatments include nongrafted 'Moneymaker' (M-NG), self-grafted 'Moneymaker' (M/Money), 'Moneymaker' grafted onto Solanum habrochaites LA1777 (M/LA1777), 'Moneymaker' grafted onto 'Shield' rootstock (M/Shield), and 'Moneymaker' grafted onto 'Multifort' rootstock (M/Multifort). Temperature regimes were $25^{\circ} \mathrm{C}$ day $/ 20^{\circ} \mathrm{C}$ night (optimal) and $15{ }^{\circ} \mathrm{C}$ day $/ 15^{\circ} \mathrm{C}$ night (suboptimal). Specific root length is calculated as total root length divided by root dry weight.

grafted onto S. lycopersicum $\times$ S. habrochaites introgressions at suboptimal root zone temperatures (Easlon et al., 2013).
Although not investigated in this study, molecular and anatomical attributes of 'Multifort' root systems are needed. Grafting cucumber (Cucumis sativus) scions onto figleaf gourd (Cucurbita ficifolia) rootstocks can improve growth, photosynthesis, and yield at suboptimal soil temperatures (Ahn et al., 1999; Zhou et al., 2007). These improvements in scion cold tolerance have been attributed to specific traits in the morphology and physiology of the fig-leaf gourd root system such as increased unsaturated fat deposition in cell lipid membranes (Lee et al., 2005a) and reduction in cold-induced suberin deposition and increased aquaporin activity (Lee et al., 2005b). These responses allow fig-leaf gourd root systems to maintain high root hydraulic conductivity and consequent movement of nutrients at lower temperatures compared with susceptible cucumber roots (Ahn et al., 1999; Lee et al., 2005b). More work is warranted to determine if the lipid composition or aquaporin activity differs between $S$. lycopersicum and S. habrochaites or rootstocks such as 'Multifort' containing $S$. habrochaites parentage. Furthermore, recent reports indicate the importance of small peptides as signaling molecules between shoot and root in root system development under situations of limited nitrogen or abiotic stress (Oh et al., 2018). Future work is needed in determining whether the quantities and types of signaling peptides differ among tomato rootstocks and how they change under conditions of abiotic stress and limited resources. Furthermore, 'Moneymaker' is the scion cultivar used in all other prior studies investigating rootstock-derived cold tolerance (Ntatsi et al., 2014, 2017; Venema et al., 2008). It would be beneficial to conduct studies using different tomato scion cultivars, both indeterminate and determinate, to determine if rootstock-derived cold tolerance is universal across scions.

The photosynthetic apparatus is sensitive to suboptimal temperatures, and changes in efficiency due to reduced temperatures can be easily observed through chlorophyll fluorescence (Allen and Ort, 2001; Kingston-Smith et al., 1997; Lynch, 1990; Maxwell and Johnson, 2000). $F_{\mathrm{v}} / F_{\mathrm{m}}$ is a measure of intrinsic PSII efficiency and, because PSII efficiency reduces with suboptimal temperatures, values of $F_{\mathrm{v}} / F_{\mathrm{m}}$ can be compared to determine the effect of temperature stress. The constitutive graft effect we observed on $F_{\mathrm{v}} / F_{\mathrm{m}}$ in the present study was also noted by Albacete et al. (2009) with rootstocks from recombinant inbred lines of $S$. lycopersicum $\times S$. cheesmaniae. Those rootstocks that improved leaf fresh weight and area also had significantly higher $F_{\mathrm{v}} / F_{\mathrm{m}}$ than non- and self-grafted controls, regardless of salinity stress. Although a different genus, our results are in agreement with Ahn et al. (1999) who found that $F_{\mathrm{v}} / F_{\mathrm{m}}$ in cucumber leaves was improved at suboptimal temperatures when grafted onto the cold-tolerant fig-leaf gourd rootstock. Ntatsi et al. (2017) did not observe an effect of temperature or graft on photosynthetic efficiency, $\mathrm{CO}_{2}$ assimilation rate, or leaf-soluble carbohydrates. These researchers used a hydroponic system to apply nutrient solutions of differing temperatures $\left(15\right.$ or $\left.25^{\circ} \mathrm{C}\right)$ directly to the root zone; however, 
Table 4. Effect of grafting and temperature on diameter class length and relative diameter class length proportions for indeterminate tomato cultivar Moneymaker grown in growth chambers maintained at either $25^{\circ} \mathrm{C}$ day $/ 20^{\circ} \mathrm{C}$ or $15{ }^{\circ} \mathrm{C}$ day $/ 15^{\circ} \mathrm{C}$ night.

\begin{tabular}{|c|c|c|c|c|c|c|c|}
\hline$\overline{\text { Temp }}$ & Graft & $\operatorname{DCL1}^{z}(\mathrm{~cm})$ & DCL2 $(\mathrm{cm})$ & DCL3 $(\mathrm{cm})$ & RDCL1 $^{y}$ & RDCL2 & RDCL3 \\
\hline \multirow{2}{*}{$25^{\circ} \mathrm{C}$ day $/ 20^{\circ} \mathrm{C}$ night } & M/Shield & $6,456.52 \mathrm{ab}$ & & & $0.8003 \mathrm{a}$ & $0.1633 \mathrm{bc}$ & \\
\hline & M/LA1777 & $5,082.75 \mathrm{bc}$ & & & $0.8006 \mathrm{a}$ & $0.1659 \mathrm{~b}$ & \\
\hline \multirow[t]{3}{*}{$15^{\circ} \mathrm{C}$ day $/ 15^{\circ} \mathrm{C}$ night } & M-NG & $3,638.27 \mathrm{~cd}$ & & & $0.7379 \mathrm{c}$ & $0.2024 \mathrm{a}$ & \\
\hline & M/Moneymaker & $3,448.16 \mathrm{~d}$ & & & $0.7437 \mathrm{c}$ & $0.2000 \mathrm{a}$ & \\
\hline & M/Shield & $3,474.33 \mathrm{~cd}$ & & & $0.7440 \mathrm{c}$ & $0.2046 \mathrm{a}$ & \\
\hline \multicolumn{8}{|l|}{ Main effects } \\
\hline \multirow[t]{2}{*}{ Temperature } & $25^{\circ} \mathrm{C}$ day $/ 20^{\circ} \mathrm{C}$ night & & $1,378.17 \mathrm{~A}$ & $314.94 \mathrm{~A}$ & & & $0.0350 \mathrm{~B}$ \\
\hline & $15^{\circ} \mathrm{C}$ day $/ 15^{\circ} \mathrm{C}$ night & & 998.94 B & $263.56 \mathrm{~B}$ & & & $0.0511 \mathrm{~A}$ \\
\hline \multirow[t]{4}{*}{ Graft } & M-NG & & $1,273.72 \mathrm{ab}$ & $318.81 \mathrm{ab}$ & & & \\
\hline & $\mathrm{M} /$ Moneymaker & & $1,115.31 \mathrm{bc}$ & $277.36 \mathrm{bc}$ & & & \\
\hline & M/Shield & & $1,143.75 \mathrm{bc}$ & $272.11 b c$ & & & \\
\hline & M/LA1777 & & $997.86 \mathrm{c}$ & $221.53 \mathrm{c}$ & & & \\
\hline
\end{tabular}

${ }^{\mathrm{z}}$ Diameter class length. DCL1 is the length of roots with diameter less than $0.5 \mathrm{~mm}$, DCL2 is the length of roots with diameter between 0.5 and $1.0 \mathrm{~mm}$, and DCL3 comprises roots with diameter greater than $1.0 \mathrm{~mm}$.

${ }^{\mathrm{y}}$ Relative diameter class length. RDCL1 is the proportion of total root length composed of roots with diameters less than $0.5 \mathrm{~mm}$, RDCL2 is the proportion of total root length composed of roots with diameter between 0.5 and $1.0 \mathrm{~mm}$, and RDCL3 comprises roots with diameter greater than $1.0 \mathrm{~mm}$.

x'Moneymaker' nongrafted.

${ }^{\text {w}}$ Means followed by the same letter within DCL or RDCL are not different (Tukey's honestly significant difference; $\alpha=0.05$ ) and represent the average of two experimental trials, four replications, and two temperature treatments for the graft main effect $(n=16$ data points for each mean); two experimental trials, four replications, and five graft treatments for the temperature main effect ( $n=40$ data points for each mean); and two experimental trials and four replications $(n=8$ data points for each mean) for the interaction of graft and temperature.

'v'Moneymaker'.

ambient temperatures were similar $\left(\approx 25^{\circ} \mathrm{C}\right)$. Tomato photosynthetic efficiency is reduced in suboptimal ambient temperatures (Walker et al., 1990). Consequently, both ambient and root zone temperatures should be considered when comparing graft effects on photosynthesis and gas exchange.

The longer root system in M/Multifort at suboptimal temperature may have maintained carbohydrate sink strength in the roots. This would allow for proper movement of photosynthate from leaves to roots, which can be observed in the reduced foliar starch concentration. Increased starch concentrations can induce feedback inhibition of photosynthesis (Goldschmidt and Huber, 1992; Paul and Foyer, 2001). The reduced starch concentrations in M/Multifort at suboptimal temperature may have allowed for increased photosynthetic efficiency and net $\mathrm{CO}_{2}$ assimilation, thus maintaining proper growth as seen in leaf area production.

The results of this study indicate that 'Multifort' can improve tolerance to suboptimal temperatures at early stages of plant development. More studies are needed to determine whether these effects are observed in mature plants during flowering and fruit production, and when plants are grown under commercial high-tunnel or open-field conditions. The ability to maintain growth for field-grown tomato when soil temperatures are suboptimal may allow growers to meet more lucrative, early season markets.

\section{Literature Cited}

Ahn, S.J., Y.J. Im, G.C. Chung, B.H. Cho, and S.R. Suh. 1999. Physiological responses of graftedcucumber leaves and rootstock roots affected by low root temperature. Scientia Hort. 81:397-408.
Ainsworth, E.A. and D.R. Bush. 2011. Carbohydrate export from the leaf: A highly regulated process and target to enhance photosynthesis and productivity. Plant Physiol. 155:64-69.

Albacete, A., C. Martínez-Andújar, M.E. Ghanem, M. Acosta, J. Sánchez-Bravo, M.J. Asins, J. Cuartero, S. Lutts, I.C. Dodd, and F. PérezAlfocea. 2009. Rootstock-mediated changes in xylem ionic and hormonal status are correlated with delayed leaf senescence, and increased leaf area and crop productivity in salinized tomato. Plant Cell Environ. 32:928938.

Allen, D.J. and D.R. Ort. 2001. Impacts of chilling temperatures on photosynthesis in warmclimate plants. Trends Plant Sci. 6:36-42.

Bloom, A.J., M.A. Zwieniecki, J.B. Passioura, L.B. Randall, N.M. Holbrook, and D.A. St. Clair. 2004. Water relations under root chilling in a sensitive and tolerant tomato species. Plant Cell Environ. 27:971-979.

Chiou, T.J. and D.R. Bush. 1998. Sucrose is a signal molecule in assimilate partitioning. Proc. Natl. Acad. Sci. USA 95:4784-4788.

Chow, P.S. and S.M. Landhäusser. 2004. A method for routine measurements of total sugar and starch content in woody plant tissues. Tree Physiol. 24:1129-1136.

Criddle, R.S., B.N. Smith, and L.D. Hansen. 1997. A respiration based description of plant growth rate responses to temperature. Planta 201:441445.

Easlon, H.M., J.S. Arsensio, D.A. St. Clair, and A.J. Bloom. 2013. Chilling-induced water stress: Variation in shoot turgor maintenance among wild tomato species from diverse habitats. Amer. J. Bot. 100:1991-1999.

Elings, A., F.L.K. Kempkes, R.C. Kaarsemaker, M.N.A. Riujs, N.J. van de Braak, and T.A. Dueck. 2005. The energy balance and energysaving measures in greenhouse tomato cultivation. Acta Hort. 691:67-74.

Equiza, M.A., J.P. Miravé, and J.A. Tognetti. 2001. Morphological, anatomical and physiological responses related to differential shoot vs. root growth inhibition at low temperature in spring and winter wheat. Ann. Bot. 87:67-76.

Fabrizio, E. 2012. Energy reduction measures in agricultural greenhouses heating: Envelope, systems and solar energy collection. Energy Build. 53:57-63.

Fennell, A. and A.H. Markhart, III. 1997. Rapid acclimation of root hydraulic conductivity at low temperature. J. Expt. Bot. 49:879-884.

Goldschmidt, E.E. 2014. Plant grafting: New mechanisms, evolutionary implications. Front. Plant Sci. 5:727.

Goldschmidt, E.E. and S.C. Huber. 1992. Regulation of photosynthesis by end-product accumulation in leaves of plants storing starch, sucrose and hexose sugars. Plant Physiol. 99:14431448.

Gupta, A.K. and N. Knaur. 2005. Sugar signaling and gene expression in relation to carbohydrate metabolism under abiotic stresses in plants. J. Biosci. 30:761-776.

Ho, M.D., J.C. Rosas, K.M. Brown, and J.P. Lynch. 2005. Root architectural tradeoffs for water and phosphorus acquisition. Funct. Plant Biol. 32:737-748.

Huang, B. and D.M. Eissenstat. 2000. Linking hydraulic conductivity to anatomy in plants that vary in specific root length. J. Amer. Soc. Hort. Sci. 125:260-264.

Kawaguchi, M., A. Taji, D. Backhouse, and M. Oda. 2008. Anatomy and physiology of graft incompatibility in solanaceous plants. J. Hort. Sci. Biotechnol. 83:581-588.

Kingston-Smith, A.H., J. Harbinson, J. Williams, and C.H. Foyer. 1997. Effect of chilling on carbon assimilation, enzyme activation, and photosynthetic electron transport in the absence of photoinhibition in maize leaves. Plant Physiol. 114:1039-1046.

Lee, S.H., S.J. Ahn, Y.J. Im, K. Cho, G.C. Chung, B-H. Cho, and O. Han. 2005a. Differential impact of low temperature on fatty acid unsaturation and lipoxygenase activity in figleaf gourd and cucumber roots. Biochem. Biophys. Res. Commun. 33:1194-1198. 
Lee, S.H., G.C. Chung, and E. Steudle. 2005b. Gating of aquaporins by low temperature in roots of chilling-sensitive cucumber and chilling-tolerant figleaf gourd. J. Expt. Bot. 56:985-995.

Lynch, D.V. 1990. Chilling injury in plants: The relevance of membrane lipids, p. 17-34. In: F. Katterman (ed.). Environmental injury to plants. Acad. Press, New York, NY.

Manavalan, L.P., S.K. Guttikonda, V.T. Nguyen, J.G. Shannon, and H.T. Nguyen. 2010. Evaluation of diverse soybean germplasm for root growth and architecture. Plant Soil 330:503514.

Maxwell, K. and G.N. Johnson. 2000. Chlorophyll fluorescence: A practical guide. J. Expt. Bot. 51:659-668.

Nieuwenhof, M., J. Jansen, and J.C. van Oeveren. 1993. Genotypic variation for relative growth rate and other growth parameters in tomato (Lycopersicon esculentum Mill.) under low energy conditions. J. Genet. Breeding 47:35-44.

Nieuwenhof, M., J. Jansen, and J.C. van Oeveren. 1997. Effects of temperature on growth and development of adult plants of genotypes of tomato (Lycopersicon esculentum Mill.). J. Genet. Breeding 51:185-193.

Nieuwenhof, M., L.C.P. Keizer, S. Zijlstra, and P. Lindhout. 1999. Genotypic variation for root activity in tomato (Lycopersicon esculentum Mill.) at different root temperatures. J. Genet. Breeding 53:271-278.

Ntatsi, G., D. Savvas, H-P. Klaring, and D. Schwarz. 2014. Growth, yield, and metabolic responses of temperature-stressed tomato to grafting onto rootstocks differing in cold tolerance. J. Amer. Soc. Hort. Sci. 139:230-243.

Ntatsi, G., D. Savvas, V. Papasotiropoulos, A. Katsileros, R.M. Zrenner, D.K. Hincha, E.
Zuther, and D. Schwarz. 2017. Rootstock suboptimal temperature tolerance determinates transcriptomic responses after long-term root cooling in rootstocks and scions of grafted tomato plants. Front. Plant Sci. 8:911.

Oh, E., P. Joon Seo, and J. Kim. 2018. Signaling peptides and receptors coordinating plant root development. Trends Plant Sci. 23: 337-351.

Paul, M.J. and C.H. Foyer. 2001. Sink regulation of photosynthesis. J. Expt. Bot. 52:1382-1400.

Rieger, M. and P. Litvin. 1999. Root system hydraulic conductivity in species with contrasting root anatomy. J. Expt. Bot. 50:201-209.

Rivard, C.L. and F.J. Louws. 2006. Grafting for disease resistance in heirloom tomatoes. North Carolina Coop. Ext. Serv. Bul. Ag-675.

Rosa, M., C. Prado, G. Podazza, R. Interdonato, J.A. Gonzalez, M. Hilal, and F.E. Prado. 2009 Soluble sugars-Metabolism, sensing and abiotic stress: A complex network in the life of plants. Plant Signal. Behav. 4:388-393.

Schwarz, D., Y. Rouphael, G. Colla, and J.H. Venema. 2010. Grafting as a tool to improve tolerance of vegetables to abiotic stresses: Thermal stress, water stress and organic pollutants. Scientia Hort. 127:162-171.

Smith, A.M. and S.C. Zeeman. 2006. Quantification of starch in plant tissues. Nat. Protoc. 1:1342-1345.

Suchoff, D.H., C.C. Gunter, and F.J. Louws. 2017. Comparative analysis of root system morphology in tomato rootstocks. HortTechnology 27:319-324

United States Department of Agriculture Economic Research Service. 2018. Yearbook-U.S. average monthly retail prices: Tomatoes, field grown. 4 Sept. 2018. <https://www.ers.usda. gov/data-products/vegetables-and-pulses-data/ by-category/>. van der Knijff, A., J. Benninga, and C. Reijnders. 2004. Energie in de glastuinbouw ontwikkelingen in de sector en op bedrijven $\mathrm{t} / \mathrm{m}$ 2003. Vol. 65. LEI Rapport 3.04.13, The Hague, The Netherlands.

Van Der Ploeg, A. and E. Heuvelink. 2005. Influence of sub-optimal temperature on tomato growth and yield: A review. J. Hort. Sci. Biotechnol. 80:652-659.

Venema, J.H., B.E. Dijk, J.M. Bax, P.R. van Hasselt, and J.T.M. Elzenga. 2008. Grafting tomato (Solanum lycopersicum) onto the rootstock of a high-altitude accession of Solanum habrochaites improves suboptimal-temperature tolerance. Environ. Expt. Bot. 63:359-367.

Venema, J.H., P. Linger, A.W. van Heusden, P.R. van Hasselt, and W. Brüggemann. 2005. The inheritance of chilling tolerance in tomato (Lycopersicon spp.). Plant Biol. 7:118-130.

Venema, J.H., F. Posthumus, and P.R. van Hasselt. 1999. Impact of suboptimal temperature on growth, photosynthesis, leaf pigments and carbohydrates of domestic and high-altitude wild $\mathrm{Lyco}$ persicon species. J. Plant Physiol. 155:711-718.

Walker, M.A., K. Peter Pauls, and B.D. McKersie. 1990. A chlorophyll fluorescence screening test to evaluate chilling tolerance in tomato. HortScience 25:334-339.

Warren, F.J., Z. Bin, G. Waltzer, M.J. Gidley, and S. Dhital. 2015. The interplant of $\alpha$-amylase and amyloglucosidase activities on the digestion of starch in in vitro enzymatic systems. Carbohydr. Polym. 117:192-200.

Zhou, Y.H., L.F. Huang, Y. Zhang, K. Shi, J.Q. Yu, and S. Nogues. 2007. Chill-induced decrease in capacity of RuBP carboxylation and associated $\mathrm{H}_{2} \mathrm{O}_{2}$ accumulation in cucumber leaves are alleviated by grafting onto Figleaf Gourd. Ann. Bot. 100:839-848. 